\title{
Quantification of Trace and Ultra-trace Impurities in U-Zr Alloy by Inductively Couple Plasma Time of Flight Mass Spectrometry (ICP-TOF-MS) After Simultaneous Separation of U and Zr
}

\author{
B.K. Nagara,b, M.K. Saxena ${ }^{\mathrm{b}}$, and B.S. Tomar ${ }^{\mathrm{a}, \mathrm{b}, *}$ \\ ${ }^{a}$ Homi Bhabha National Institute (HBNI), Anushaktinagar, Mumbai-400094, India \\ ${ }^{\text {b}}$ Radioanalytical Chemistry Division, Bhabha Atomic Research Centre, Mumbai-400085, India
}

\section{INTRODUCTION}

The metallic nuclear fuels based on U-Zr and U-Pu-Zr alloys are preferred in fast breeder reactors compared to conventional oxides and carbides owing to their high fissile density, high burnup, high breeding ratio, less doubling time, good fuel-clad compatibility, high thermal conductivity, and inherent passive safety. In India, fabrication and irradiation studies are being pursued in order to develop metallic fuel-based fast breeder reactors (FBR) $(1,2)$. Metallic fuels have been used in nuclear reactors in the past (EBR I\&II USA) and are also proposed for advanced nuclear reactors, such as traveling wave reactor (TWR), fusion-fission hybrid reactor (FFHR), sodium-cooled fast reactors (SFR), etc. $(3,4)$. In the fast breeder reactors, U-Pu-Zr fuel is used in the main core, whereas $\mathrm{U}-\mathrm{Zr}$ is used as blanket material for breeding.

Chemical characterization of nuclear fuels for major, trace, and ultra-trace elements is very important to ensure the desired behavior of fuels during reactor operation. The elements, whose presence above the specification limit could lead to detrimental effects, have very stringent specifications $(5,6)$. Hence, it is essential to have precise and accurate knowledge of their concentrations in the starting raw materials and fabricated fuel prior to its loading into the nuclear reactors. Several analytical

*Corresponding authors

bstomar@barc.gov.in,

el: +91-22-25595006

\section{ABSTRACT}

A methodology has been developed for the determination of trace and ultra-trace metallic impurities in U-Zr alloy fuel by inductively coupled plasma mass spectrometry (ICP-MS) after solvent extraction of the bulk matrix. A detailed study was performed to optimize the concentration of tri-n-octyl phosphine oxide (TOPO), tri-n-butyl phosphate (TBP), nitric acid, and hydrochloric acid for maximum removal of the matrix elements (U and $\mathrm{Zr}$ ). The ratio of metal oxide to metal $\left(\mathrm{MO}^{+} / \mathrm{M}^{+}\right)$and doubly charged to singly charged zirconium $\left(\mathrm{Zr}^{++} / \mathrm{Zr}^{+}\right)$ was studied for correction of spectroscopic interference. The non-spectroscopic matrix effect was studied for rare earth and cadmium. The standard addition method was performed for recovery study of the trace and ultra-trace elements. Recovery of 36 elements (Al, Ba, Bi, Cd, Ce, Co, Cr, Cs, Dy, Eu, Er, Ga, Gd, Ir, $\mathrm{Ho}, \mathrm{La}, \mathrm{Lu}, \mathrm{Mn}, \mathrm{Nd}, \mathrm{Ni}, \mathrm{Pb}, \mathrm{Pr}$, $\mathrm{Pt}, \mathrm{Rh}, \mathrm{Rb}, \mathrm{Ru}, \mathrm{Sc}, \mathrm{Sm}, \mathrm{Sr}, \mathrm{Tb}, \mathrm{Te}$, $\mathrm{Tm}, \mathrm{V}, \mathrm{Y}$, and $\mathrm{Yb}$ ) was found to be more than $90 \%$ with the $\%$ RSD $<10$. The matrix (U\&Zr) concentration after separation was $<10 \mu \mathrm{g} \mathrm{mL}^{-1}$. The instrumental detection limit (IDL) and method detection limit (MDL) were found to be in the range 0.01-1.1 $\mu \mathrm{g} \mathrm{L}^{-1}$ and 1.0-25.0 $\mu \mathrm{g} \mathrm{kg}^{-1}$, respectively. The separation method was validated using ${ }^{152}+{ }^{154} \mathrm{Eu}$ as tracer for the rare earth elements. techniques, i.e., neutron activation analysis (NAA), graphite furnace atomic absorption spectrometry (GFAAS), inductively coupled plasma atomic emission spectrometry (ICP-AES), total reflection X-ray fluorescence (TXRF), UV-visible spectroscopy, inductively coupled plasma mass spectrometry (ICPMS), etc., are used in practice for the determination of trace impurities in the nuclear fuels (7-9). Each technique has its advantages and disadvantages. However, sensitivity and matrix interference are the two key elements in the determination of trace impurities in uraniumbased nuclear materials. Selection of the technique depends upon sample size, detection limit, sensitivity, and sample throughput.

Several studies have been reported for the analysis of $\mathrm{U}-\mathrm{Zr}$ (10-12) and U-Pu-Zr alloy (13). However, in these methods, a relatively low number of elements were quantified, also the recovery was not complete for the elements.

Owing to the very low detection limit, low spectroscopic interference, high sample throughput, high sensitivity, and multi-element capability, ICP-MS is the technique of choice for the trace analysis in a U-Zr matrix. However, analysis of trace and ultra-trace elements with high concentrations of matrix elements leads to non-spectroscopic interference and memory effects as the sample solution is passed through a fine capillary of the nebulizer, and the ions are transmitted to the detector through a small hole of the sampler and skimmer cones. The sample solutions having high 
total dissolved solid (TDS) choke the capillary of the nebulizer and the holes of the sampler and skimmer, which introduces significant systematic and random error in the measurements. Further, a long washing time is required to remove the memory effect from the matrix elements. Considering these problems, it is important to separate the matrix before quantification of the traces using ICP-MS.

Extraction of uranium has been reported using dibenzo-24-crown-8 (14), benzyloctadecyldimethylammonium chloride (15), cyanex-272 (16), cyanex-301 (17), di-2-ethylhexyldithiophosphoric acid (18), $\mathrm{N}, \mathrm{N}$-dihexanoylpiperazine (19), dicyclohexyl-18-crown-6 (20), octaethyltetraamidopyrophosphate (21), 1-(4-tolyl)-2-methyl-3-hydroxy4-pyridone (22), tri-butyl phosphate (23), tri-n-octyl phosphine oxide $(24,25)$, etc. Similarly, extraction of zirconium has been reported using aliquat-336 (26), tri-2-ethyl hexyl amine (27), cynax-923 (28), tributyl phosphate (29), tri-n-octyl phosphine oxide $(30,31)$, etc. For the matrix under study, both $U$ and $\mathrm{Zr}$ are to be separated. It is important to have a single solvent extractant which can separate both species present in the sample simultaneously. As listed above, TBP can be used for both $\mathrm{U}$ and $\mathrm{Zr}$. However, the experimental conditions required for the complete separation is different for $\mathrm{U}$ and $\mathrm{Zr}$. It is also possible to utilize the synergistic solvent extraction procedure, where more than one extractant is used simultaneously as discussed in a review by R. Sarkar et al. (32). TBP is used in the PUREX process for the separation of uranium from nitric acid medium, while TOPO is known to extract $\mathrm{Zr}$ from $\mathrm{HCl}$ medium $(33,34)$. In the present work, the simultaneous extraction of $\mathrm{U}$ and $\mathrm{Zr}$ was investigated using a combination of tri-n-butyl phosphate (TBP) and tri-n-octyl phosphine oxide (TOPO). A detailed study was carried out to optimize the experimental conditions for the simultaneous extraction of $U$ and $\mathrm{Zr}$, leaving the impurities in the solution. Trace analysis of the sample prepared for the developed separation method was carried out by ICP-MS and due to the unavailability of certified reference material (CRM) of U-Zr, validation was carried out using the standard addition method.

\section{EXPERIMENRAL}

\section{Instrumentation}

An inductively coupled plasmaorthogonal acceleration-time of flight mass spectrometer (ICP-oaTOF-MS) model Optimass 8000R (GBC, Australia) was employed for the quantification of trace and ultratrace elements in U-Zr alloy. Details of the instrumental operating parameters are given in (35). A 3'X3" NaI(Tl) well-type detector coupled to a multichannel analyzer (Electronic Corporation of India Limited) was used to validate the separation procedure using ${ }^{152}+{ }^{154} \mathrm{Eu}$ as tracer. Eppendorf ${ }^{\circledR}$ micropipettes,

Nalgene ${ }^{\circledR}$ PP measuring flask, separating funnels, and Teflon ${ }^{\circledR}$ PFA beakers were used throughout the experiment.

\section{Reagents and Solutions}

TBP (Merck), TOPO (Aldrich), toluene (SRL), Suprapur ${ }^{\circledR} \mathrm{HNO}_{3}$ and $\mathrm{HCl}$ (Merck) were used for solvent extraction and preparation of the sample. De-ionized water having a resistivity of $18 \mathrm{M} \Omega \cdot \mathrm{cm}$ (Milli$\mathrm{Q}^{\mathrm{TM}}$ system, Millipore Corporation, USA) was used for dilution. The ICP standards of $1000 \mathrm{mg} \mathrm{L}^{-1}(\mathrm{BDH})$ were diluted appropriately to prepare multi-element standard solutions.

\section{Preparation of Aqueous and Organic Medium}

The aqueous phase medium was optimized using a mixture of $4 \mathrm{M}$ $\mathrm{HCl}$ and $4 \mathrm{M} \mathrm{HNO}$. The final vol- ume was made up to $100 \mathrm{~mL}$ using Milli-Q water. The organic phase was prepared by adding a weighed amount of TOPO to $30 \%$ TBP in toluene to make the TOPO concentration as $0.1 \mathrm{M}$.

\section{Preparation of Synthetic Solutions}

Due to non-availability of certified reference material (CRM) for $\mathrm{U}-\mathrm{Zr}$ alloy, a synthetic solution of U-Zr was prepared. Nuclear-grade uranium and zirconium metals were dissolved separately and mixed together so as to prepare working standards of concentration $94 \mathrm{mg} \mathrm{mL}^{-1} \mathrm{U}$ and $6 \mathrm{mg} \mathrm{mL}^{-1} \mathrm{Zr}$. Aliquots of this solution were spiked with known amounts of trace elements in this study.

\section{Dissolution of U-Zr Alloy}

$\mathrm{U}-\mathrm{Zr}$ could be dissolved in concentrated $\mathrm{HCl}$ and $\mathrm{HNO}_{3}$; however, the dissolution was slow. It took around 1.0-1.5 hours for complete dissolution, which was accelerated by addition of a few drops of HF. On completion of the dissolution, HF was removed by repetitive evaporation of the solution to near dryness with addition of $\mathrm{HNO}_{3}-\mathrm{HCl}$ (4M) solution. Finally, the dissolved sample was made in $\mathrm{HNO}_{3}-\mathrm{HCl}$ (4M) medium for solvent extraction studies.

\section{Separation of Matrix Elements}

In order to develop a solvent extraction-based separation procedure, a detailed study was carried out using TBP and TOPO. For the separation studies, toluene was selected as the diluent. Many authors have used carbon tetrachloride as diluent $(11,12)$; however, it is carcinogenic and aids the ozone depletion (36). Further, it forms $\mathrm{CCl}_{4} \cdot 2 \mathrm{TBP}$ with TBP, which decreases the extraction efficiency due to a decrease in effective concentration of TBP in the organic phase. Experiments were performed in a fume-hood using sepa- 
rating funnels. The volume of aqueous and organic phases taken for the equilibration was $5 \mathrm{~mL}$ each.

\section{Aqueous Phase Analysis}

After the separation, the aqueous phase was evaporated to near dryness and re-dissolved in $1 \% \mathrm{HNO}_{3}$ to a known volume. $\mathrm{Zr}$ and the trace elements were determined by ICP-MS, whereas U was determined by a spectrophotometric method using Arsenazo-III as a chromogenic agent (37).

\section{RESULT AND DISCUSSION}

\section{Extraction of $\mathrm{Zr}$ from $\mathrm{HCl}$ and $\mathrm{HNO}_{3}$ Medium in TBP}

The extraction of $U$ in TBP is reported to increase with an increasing concentration of hydrochloric acid, with the appearance of a third phase formation (at uranium concentrations $>1 \mathrm{M}$ ) at $5 \mathrm{M} \mathrm{HCl}$ (38). In the PUREX process, the extraction of $U$ is carried out from $4 \mathrm{M}$ nitric acid in 30\% TBP. Therefore, it was important to know the extraction of $\mathrm{Zr}$ in TBP in the conditions suitable for $\mathrm{U}$ extraction.

A set of separation studies were carried out wheras $\mathrm{Zr}$ was extracted from varying concentrations of $\mathrm{HCl}$ or $\mathrm{HNO}_{3}$ in $30 \%$ TBP. For an acid concentration of $7 \mathrm{M}$, the extraction in both acid media increases up to $60 \%$ (Figure 1).
Extraction of zirconium in high concentrations of $\mathrm{HNO}_{3}(>8 \mathrm{M})$ with TBP has been reported (39), but excess nitrate concentration promotes the formation of unextractable anions of uranium such as $\left[\mathrm{UO}_{2}\left(\mathrm{NO}_{3}\right)_{3}\right]^{-}(40)$. Further, at higher concentrations of $\mathrm{HNO}_{3}$ $(>5 \mathrm{M})$, the probability of extraction of trace analytes increases $(41,42)$.

Though both $\mathrm{U}$ and $\mathrm{Zr}$ can be extracted in the TBP, the conditions required for their individual satisfactory extractions are different.

\section{Extraction of $\mathrm{Zr}$ in TOPO}

In case of TOPO, U extraction from $\mathrm{HNO}_{3}(4-5 \mathrm{M})$ medium is nearly quantitative ( 95\%); however, for the quantitative extraction of $\mathrm{Zr}, \mathrm{HCl}$ medium is required. Therefore, detailed studies were carried out to optimize the conditions for a mixture of acids $\left(\mathrm{HNO}_{3}\right.$ and $\mathrm{HCl}$ ) and that of the extractants (TBP and TOPO). Extraction of zirconium in TOPO was studied individually in $\mathrm{HNO}_{3}$ and $\mathrm{HCl}$. The condition was optimized using $1000 \mu \mathrm{g}$ of zirconium with varying concentrations of $\mathrm{HCl}, \mathrm{HNO}_{3}$, and TOPO. The results show that $\mathrm{Zr}$ is extracted up to $99 \%$ at $\mathrm{HCl}$ concentration above $4 \mathrm{M} \mathrm{HCl}$ (Figure 1a), while in $\mathrm{HNO}_{3}$ medium the $\mathrm{Zr}$ extraction increased with acid molarity reaching around $25 \%$ at $4 \mathrm{M} \mathrm{HNO}_{3}$. In a separate study, extraction of $\mathrm{Zr}$ from a mixture of
$\mathrm{HNO}_{3}(4 \mathrm{M})$ and $\mathrm{HCl}(4 \mathrm{M})$ to TOPO (concentration varied) was carried out (Figure 1b), wherein Zr extraction was found to be better than 99\% at and above $0.1 \mathrm{M}$ TOPO.

\section{Effect of TBP}

In view of the efficient extraction of $U$ in TBP, a set of experiments was carried out by adding $30 \%$ TBP to the above optimized organic phase (0.1M TOPO in toluene). Synthetic samples of $\mathrm{Zr}$ (6 mg) and varying concentrations of $\mathrm{U}(0-125 \mathrm{mg})$ in $\mathrm{HNO}_{3}-\mathrm{HCl}$ (4M) medium were equilibrated with the organic phase. The amount of $\mathrm{U}$ and $\mathrm{Zr}$ taken was important because it represents the $\mathrm{U}$ and $\mathrm{Zr}$ content in the dissolved U-Zr samples. The percentage extraction of $U$ and the effect of an increasing $\mathrm{U}$ concentration on $\mathrm{Zr}$ extraction are plotted in Figure 2. It was found that the extraction of uranium (up to $125 \mathrm{mg}$ ) was better than $95 \%$ as given in Figure 2a. On the other hand, the percentage extraction of $\mathrm{Zr}$ was above $97 \%$ (lower than 99\% observed with only $\mathrm{Zr}$ ) with an increasing uranium concentration (Figure 2b).

\section{Non-spectroscopic Interference}

Since a fraction of $U(4-5 \%)$ and $\mathrm{Zr}$ (2-3\%) was still present in the aqueous phase with the trace analytes, it was decided to study the effect of the remaining $\mathrm{U}$ and $\mathrm{Zr}$
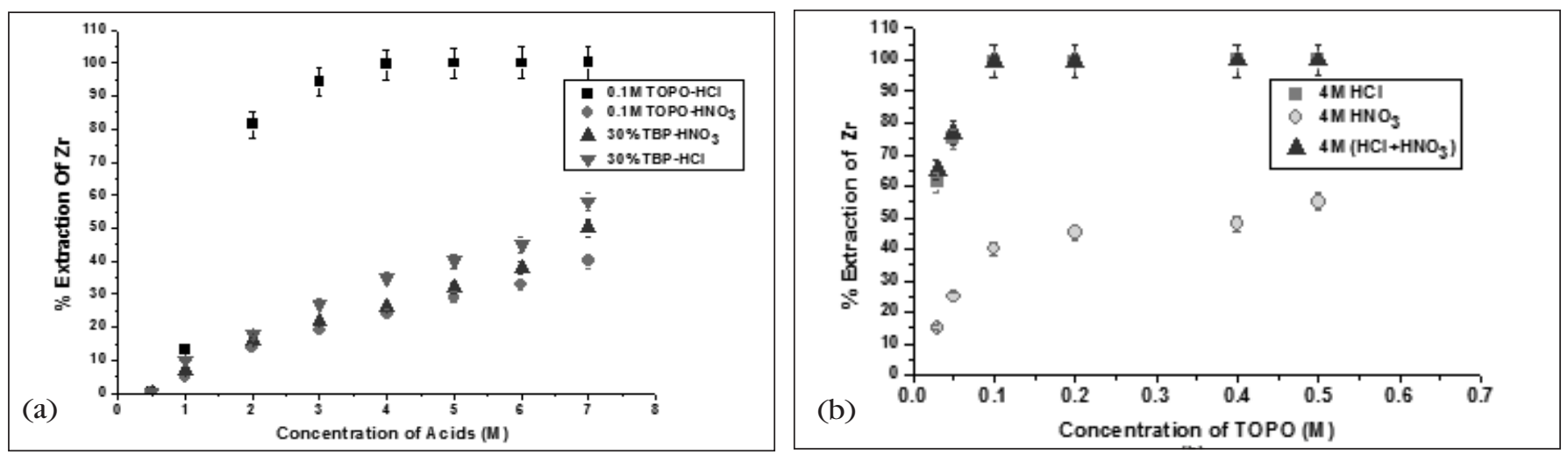

Fig. 1. Percentage extraction of zirconium: (a) with 30\% TBP and $0.1 \mathrm{M} \mathrm{TOPO}$ at different concentration of $\mathrm{HNO}_{3}$ and $\mathrm{HCl}$ and (b) with different concentration of TOPO at $4 \mathrm{M} \mathrm{HNO}, 4 \mathrm{M} \mathrm{HCl}$ and $4 \mathrm{M} \mathrm{HNO}-4 \mathrm{M} \mathrm{HCl}$ mixture. 
matrix on the analytes of interest. Literature reports show that moderate amounts (0.01-0.5\%) of the matrix ions can change the analyte signal significantly when analyzed by ICP-MS (43-45).

To study the non-spectroscopic matrix effect, a range of samples was prepared with the same concentration of analytes (100 $\mathrm{ng} \mathrm{mL}^{-1}$ of rare earth and cadmium) and varying concentrations of $\mathrm{U}-\mathrm{Zr}(0$, 50, 100, 200, 300, 400, 500, 600, and $700 \mu \mathrm{g} \mathrm{mL} \mathrm{m}^{-1}$ ). Each sample was analyzed for the trace analytes by ICP-MS. It was observed that up to $100 \mu \mathrm{g} \mathrm{mL} \mathrm{m}^{-1}$ of matrix had no significant effect on the analyte signal (Figure 3), above which the sensitivity decreased significantly.
In order to have quantitative separation of the matrix $\left(\leq 100 \mu \mathrm{g} \mathrm{mL}^{-1}\right)$, more than one contact with the organic phase was required. The $\mathrm{U}$ and $\mathrm{Zr}$ content in the aqueous phase after three contacts was found to be 10 and $0.1 \mu \mathrm{gL}^{-1}$, respectively.

\section{Recovery of Analytes}

With the combination of TBP and TOPO in the organic phase and that of $\mathrm{HNO}_{3}$ and $\mathrm{HCl}$ in the aqueous phase, quantitative extraction was possible for $\mathrm{U}$ and $\mathrm{Zr}$. To use this method for matrix separation, it was important to study the recovery of the analytes during the extraction procedure. The recoveries were studied with and without the matrix. In the first experiment, 55 elements were studied in the absence of $U$ and $\mathrm{Zr}$ matrix. Aqueous solutions containing $100 \mathrm{ppb}$ of individual elements in $\mathrm{HNO}_{3}-\mathrm{HCl}$ (4M) were equilibrated with equal volume of $0.1 \mathrm{M}$ TOPO and 30\% TBP (in toluene). Analysis of the aqueous phase by ICP-MS showed that 36 elements were quantitatively retained in the aqueous phase, while the retention was less for the remaining elements as given in Table I. Further studies are required for improving the retention of these elements in the aqueous phase to enable their quantification. In the second experiment, the above procedure was performed in the presence of $100 \mathrm{mg}$
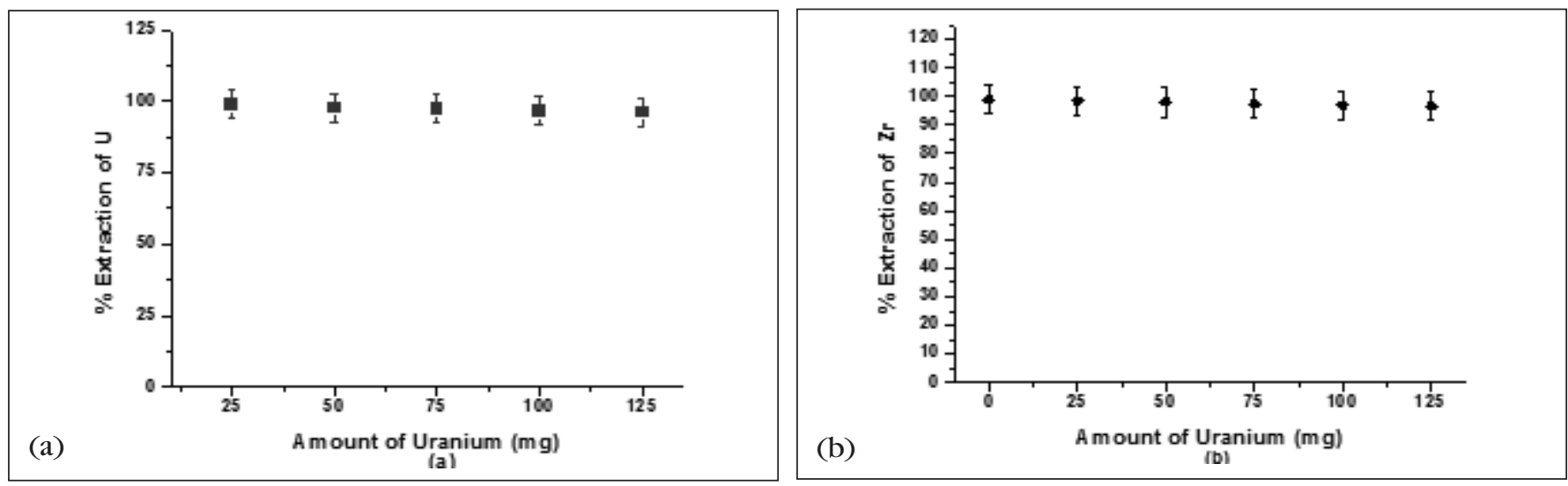

Fig. 2. Percentage extraction with 0.1M TOPO-30\%TBP (in toluene) of: (a) Uranium at its different amount, (b) Zirconium in presence of varying amount of $U$.

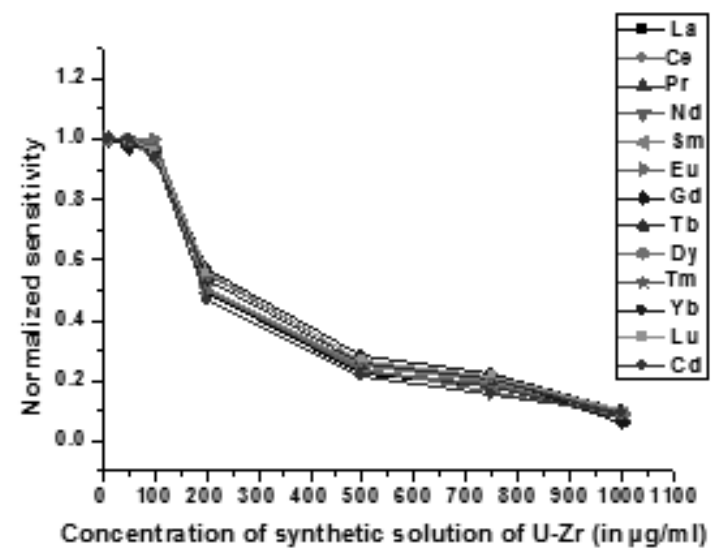

TABLE I

Retention Studies of 55 Elements (each at100 ppb) in the Absence of the Matrix

\begin{tabular}{|c|c|c|}
\hline $\begin{array}{l}\text { Retention } \\
\text { (\%) }\end{array}$ & $\begin{array}{c}\text { Total } \\
\text { Elements }\end{array}$ & Elements \\
\hline $95-100$ & 36 & $\begin{array}{l}\mathrm{Al}, \mathrm{Ba}, \mathrm{Bi}, \mathrm{Cd}, \mathrm{Ce}, \mathrm{Co}, \mathrm{Cr}, \mathrm{Cs}, \\
\mathrm{Cu}, \mathrm{Dy}, \mathrm{Eu}, \mathrm{Er}, \mathrm{Ga}, \mathrm{Gd}, \mathrm{Ir}, \mathrm{La}, \\
\mathrm{Lu}, \mathrm{Mg}, \mathrm{Mn}, \mathrm{Nd}, \mathrm{Ni}, \mathrm{Pb}, \mathrm{Pr}, \\
\mathrm{Pt}, \mathrm{Rb}, \mathrm{Rh}, \mathrm{Ru}, \mathrm{Sc}, \mathrm{Sm}, \mathrm{Sr}, \mathrm{Tb}, \\
\text { Te, Tm, V, Y, and Yb }\end{array}$ \\
\hline $60-70$ & 2 & $\mathrm{Pd}, \mathrm{Sb}$ \\
\hline $60-30$ & 10 & $\begin{array}{l}\mathrm{Ag}, \mathrm{As}, \mathrm{B}, \mathrm{Fe}, \mathrm{Mo}, \mathrm{Nb}, \mathrm{Re} \\
\mathrm{Se}, \mathrm{Sn}, \text { and } \mathrm{Zn}\end{array}$ \\
\hline$<10$ & 7 & Hf, Hg, Ho, Li Ta, Ti ,W \\
\hline
\end{tabular}

Fig. 3. Variation in sensitivity with matrix concentration. 
synthetic U (94 mg) + Zr (6 mg) solution. The results indicated that retention of the analytes was the same as observed without the matrix.

\section{Standard Addition Method for Validation}

The separation method was validated by standard addition method. Four aliquots of the synthetic U-Zr solutions $(1.0 \mathrm{ml})$ were taken in $\mathrm{HNO}_{3}-\mathrm{HCl}(4 \mathrm{M})$. In the three aliquots, multi-element standards of 55 elements (Ag, Al, As, B, Ba, Bi, $\mathrm{Cd}, \mathrm{Ce}, \mathrm{Co}, \mathrm{Cr}, \mathrm{Cs}, \mathrm{Cu}, \mathrm{Dy}, \mathrm{Er}, \mathrm{Eu}$, $\mathrm{Fe}, \mathrm{Ga}, \mathrm{Gd}$, Hf, Hg, Ho, Ir, La, Li, $\mathrm{Lu}, \mathrm{Mg}, \mathrm{Mn}, \mathrm{Mo}, \mathrm{Nb}, \mathrm{Nd}, \mathrm{Ni}, \mathrm{Pb}, \mathrm{Pd}$, $\mathrm{Pr}, \mathrm{Pt}, \mathrm{Rb}, \mathrm{Re}, \mathrm{Rh}, \mathrm{Ru}, \mathrm{Sb}, \mathrm{Sc}, \mathrm{Se}$, Sm, Sn, Sr, Ta, Tb, Te, Ti, Tm, V, W, $\mathrm{Y}, \mathrm{Yb}$ and $\mathrm{Zn}$ ), each having 1, 2, and $5 \mu \mathrm{g}$, were added, while one aliquot was taken as such. The matrix elements $U$ and $\mathrm{Zr}$ were separated simultaneously using the developed solvent extraction method described above. It was found that the 36 elements of $\mathrm{Al}$, $\mathrm{Ba}, \mathrm{Bi}, \mathrm{Cd}, \mathrm{Ce}, \mathrm{Co}, \mathrm{Cr}, \mathrm{Cs}, \mathrm{Cu}, \mathrm{Dy}$, $\mathrm{Eu}, \mathrm{Er}, \mathrm{Ga}, \mathrm{Gd}$, Ir, La, Lu, Mg, Mn, $\mathrm{Nd}, \mathrm{Ni}, \mathrm{Pb}, \mathrm{Pr}, \mathrm{Pt}, \mathrm{Rb}, \mathrm{Rh}, \mathrm{Ru}, \mathrm{Sc}$, $\mathrm{Sm}, \mathrm{Sr}, \mathrm{Tb}, \mathrm{Te}, \mathrm{Tm}, \mathrm{V}, \mathrm{Y}$ and $\mathrm{Yb}$ were retained at $>90 \%$, while the 19 elements of Ag, As, B, Fe, Hf, Hg, Ho, Li, Mo, Nb, Pd, Re, Sb, Se, Sn, Ta, $\mathrm{Ti}, \mathrm{W}$, and $\mathrm{Zn}$ were retained poorly. The instrument was externally calibrated using six multi-element standards having concentrations in the range of $50-750 \mu \mathrm{g} \mathrm{L}^{-1}$. ${ }^{115}$ In was used as internal standard to monitor any drift during the analysis. The recovery results are listed in Table II (see page 190).

\section{Study of Isobaric Interferences}

The details of elements forming oxides, hydroxides, and doubly charged species that can cause interference are given in the literature (46-48). A discussion for correction of this kind of interferences can be found in $(49,50)$. Based on these procedures, metal oxide to metal ratios $\left(\mathrm{MO}^{+} / \mathrm{M}^{+}\right)$were deter- mined for the elements which show this interference. For this, 10-100 $\mu \mathrm{g} \mathrm{L}^{-1}$ of each element was subjected to ICP-MS measurement for signal intensity, and their ratio was determined. The ratios were used for correction of spectroscopic interferences.

\section{Detection Limit}

Both the instrument detection limits (IDLs) and the method detection limits (MDLs) were determined for the analytes of interest as per the reported procedure (51). The IDLs were obtained by analyzing the elements in $1 \%(\mathrm{v} / \mathrm{v})$ pure $\mathrm{HNO}_{3}$ solution for all of these elements. For MDL determination, the discussed separation procedure was followed exactly in the absence of the sample, and the solutions were analyzed by ICP-MS. The $3 \sigma$ values of IDLs and MDLs are tabulated in Table III.

\section{Validation of Separation Proce- dure by $\gamma$-Spectrometry Using ${ }^{152}+{ }^{154}$ Eu Tracer}

Recovery study by $\gamma$-spectrometry is a unique technique to validate any proposed separation procedure as it does not require any blank correction on the spiked amount. To validate the recovery of rare earth elements, ${ }^{152}+{ }^{154} \mathrm{Eu}$ tracer was used. The tracer was mixed with natural europium solution in such a manner that concentration of Eu in the stock solution becomes $1 \mu \mathrm{g} \mathrm{mL} \mathrm{mL}^{-1}$. $1.0 \mathrm{~mL}$ of the stock solution was taken as reference and $1.0 \mathrm{~mL}$ mixed with $100 \mathrm{mg}$ U-Zr solution. The $\mathrm{U}$ and $\mathrm{Zr}$ matrix was separated by the optimized solvent extraction procedure and the tracer retained in the aqueous phase was determined by measuring $344 \mathrm{keV}$ gamma energy in a NaI(Tl) detector. The recovery of tracer was calculated with respect to the reference. The results of the recovery studies are listed in Table IV.

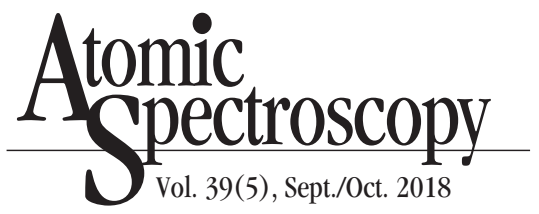

TABLE III

Instrument Detection Limit (IDL) and Method Detection Limit (MDL) for Analytes ( $N=10)$

\begin{tabular}{|c|c|c|}
\hline $\begin{array}{l}\text { Elements } \\
\text { (Measured } \\
\text { Isotope Mass) }\end{array}$ & $\begin{array}{c}\mathrm{IDL} \\
\left(\mu \mathrm{g} \mathrm{L}^{-1}\right)\end{array}$ & $\begin{array}{c}\mathrm{MDL} \\
\left(\mu \mathrm{g} \mathrm{kg}^{-1}\right)\end{array}$ \\
\hline $\mathrm{Al}(27)$ & 0.2 & 22.0 \\
\hline $\mathrm{Ba}(133)$ & 0.7 & 4.1 \\
\hline Bi (208) & 1.1 & 2.3 \\
\hline Cd (114) & 0.7 & 2.2 \\
\hline Ce (140) & 0.01 & 1.4 \\
\hline $\operatorname{Co}(59)$ & 0.02 & 2.4 \\
\hline $\operatorname{Cr}(52)$ & 0.10 & 1.5 \\
\hline Cs (133) & 0.12 & 5.1 \\
\hline $\mathrm{Cu}(63)$ & 0.15 & 11.5 \\
\hline Dy (164) & 0.01 & 4.3 \\
\hline Eu (153) & 0.01 & 1.0 \\
\hline $\operatorname{Er}(166)$ & 0.05 & 1.1 \\
\hline $\mathrm{Ga}(69)$ & 0.26 & 0.5 \\
\hline Gd (158) & 0.01 & 0.5 \\
\hline Ir (193) & 0.01 & 2.8 \\
\hline Ho (165) & 0.05 & 8.7 \\
\hline La (139) & 0.02 & 0.9 \\
\hline Lu (175) & 0.02 & 0.7 \\
\hline $\operatorname{Mg}(24)$ & 0.10 & 25.0 \\
\hline $\operatorname{Mn}(55)$ & 0.03 & 6.7 \\
\hline Nd (146) & 0.01 & 1.9 \\
\hline $\mathrm{Ni}(58)$ & 0.02 & 17.8 \\
\hline $\mathrm{Pb}(208)$ & 0.03 & 3.8 \\
\hline $\operatorname{Pr}(141)$ & 0.01 & 0.7 \\
\hline Pt (195) & 0.02 & 1.9 \\
\hline $\mathrm{Rb}(85)$ & 0.05 & 1.4 \\
\hline $\mathrm{Rh}(103)$ & 0.05 & 1.0 \\
\hline Ru (102) & 0.03 & 1.2 \\
\hline Sc (45) & 0.03 & 14.9 \\
\hline $\operatorname{Sm}(152)$ & 0.01 & 1.5 \\
\hline $\mathrm{Tb}$ (159) & 0.01 & 0.9 \\
\hline $\mathrm{Te}(130)$ & 0.3 & 6.3 \\
\hline $\operatorname{Tm}(169)$ & 0.02 & 0.9 \\
\hline $\mathrm{V}(51)$ & 0.03 & 7.5 \\
\hline Y (89) & 0.05 & 1.7 \\
\hline $\mathrm{Yb}(174)$ & 0.03 & 1.3 \\
\hline
\end{tabular}

Note: MDL calculated in absence of original sample.

TABLE IV

Result of Recovery Studies by $\gamma$-Spectrometry (N=10, 60 s Counting)

\begin{tabular}{lc} 
Sr. No. & Recovery of Eu (\%) \\
\hline Sample-1 & $98 \pm 1$ \\
Sample-2 & $97 \pm 1$ \\
Sample-3 & $98 \pm 1$ \\
\hline
\end{tabular}


TABLE II

\begin{tabular}{|c|c|c|c|c|c|c|c|c|c|c|c|}
\hline \multicolumn{12}{|c|}{$\begin{array}{l}\text { Recovery of Trace Elements in Synthetic U-Zr Sample } \\
\text { (Sample Amount }=0.1 \mathrm{~g} \text {, Volume }=25 \mathrm{~mL}, \mathbf{N}=10)\end{array}$} \\
\hline $\begin{array}{l}\text { Ele- } \\
\text { ments }\end{array}$ & $\begin{array}{c}\text { Added } \\
(\mu \mathrm{g})\end{array}$ & $\begin{array}{l}\text { Found } \\
(\mu \mathrm{g})\end{array}$ & $\begin{array}{l}\text { Recovery } \\
(\%)\end{array}$ & $\begin{array}{l}\text { Ele- } \\
\text { ments }\end{array}$ & $\begin{array}{l}\text { Added } \\
(\mu \mathrm{g})\end{array}$ & $\begin{array}{c}\text { Found } \\
(\mu \mathrm{g})\end{array}$ & $\begin{array}{l}\text { Recovery } \\
(\%)\end{array}$ & $\begin{array}{l}\text { Ele- } \\
\text { ments }\end{array}$ & $\begin{array}{c}\text { Added } \\
(\mu \mathrm{g})\end{array}$ & $\begin{array}{c}\text { Found } \\
(\mu \mathrm{g})\end{array}$ & $\begin{array}{l}\text { Recovery } \\
(\%)\end{array}$ \\
\hline \multirow[t]{4}{*}{$\mathrm{Al}$} & 0 & $0.11 \pm 0.01$ & - & \multirow{4}{*}{ Gd } & 2 & $2.21 \pm 0.14$ & $95.5 \pm 8.8$ & \multirow[t]{4}{*}{$\mathrm{Rb}$} & 0 & BDL & - \\
\hline & 1 & $1.10 \pm 0.04$ & $99.0 \pm 9.7$ & & 5 & $4.98 \pm 0.27$ & $93.6 \pm 8.0$ & & 1 & $0.91 \pm 0.08$ & $91.0 \pm 8.0$ \\
\hline & 2 & $1.94 \pm 0.11$ & $91.5 \pm 9.8$ & & 0 & BDL & - & & 2 & $1.86 \pm 0.15$ & $93.0 \pm 7.5$ \\
\hline & 5 & $4.98 \pm 0.19$ & $97.4 \pm 9.6$ & & 1 & $1.0 \pm 0.02$ & $98.0 \pm 5.0$ & & 5 & $5.12 \pm 0.49$ & $102.4 \pm 9.8$ \\
\hline \multirow[t]{4}{*}{$\mathrm{Ba}$} & 0 & $0.12 \pm 0.01$ & - & & 2 & $2.01 \pm 0.10$ & $99.5 \pm 4.9$ & \multirow[t]{4}{*}{$\mathrm{Rh}$} & 0 & BDL & - \\
\hline & 1 & $1.10 \pm 0.04$ & $99.0 \pm 9.0$ & & 5 & $4.99 \pm 0.20$ & $99.4 \pm 4.0$ & & 1 & $0.98 \pm 0.09$ & $98.0 \pm 9.0$ \\
\hline & 2 & $2.1 \pm 0.09$ & $98.0 \pm 9.4$ & Ir & 0 & BDL & - & & 2 & $1.95 \pm 0.15$ & $97.5 \pm 7.5$ \\
\hline & 5 & $5.05 \pm 0.21$ & $98.6 \pm 9.2$ & & 1 & $0.95 \pm 0.08$ & $95.0 \pm 8.4$ & & 5 & $5.10 \pm 0.45$ & $102.0 \pm 9.0$ \\
\hline \multirow[t]{4}{*}{$\mathrm{Bi}$} & 0 & $1.1 \pm 0.05$ & - & & 2 & $2.01 \pm 0.17$ & $100.5 \pm 8.5$ & \multirow[t]{4}{*}{$\mathrm{Ru}$} & 0 & BDL & - \\
\hline & 1 & $2.05 \pm 0.15$ & $95.0 \pm 7.0$ & & 5 & $4.91 \pm 0.48$ & $98.2 \pm 9.6$ & & 1 & $0.93 \pm 0.08$ & $93.0 \pm 8.6$ \\
\hline & 2 & $3.08 \pm 0.25$ & $99.0 \pm 9.2$ & Ho & 0 & BDL & - & & 2 & $1.88 \pm 0.16$ & $94.0 \pm 8.0$ \\
\hline & 5 & $5.89 \pm 0.25$ & $95.8 \pm 6.1$ & & 1 & $0.93 \pm 0.07$ & $93.0 \pm 7.5$ & & 5 & $4.98 \pm 0.42$ & $99.6 \pm 8.4$ \\
\hline \multirow[t]{4}{*}{$\mathrm{Cd}$} & 0 & BDL & - & & 2 & $1.91 \pm 0.18$ & $95.5 \pm 9.0$ & \multirow[t]{4}{*}{ Sc } & 0 & BDL & - \\
\hline & 1 & $1.00 \pm 0.04$ & $99.0 \pm 4.0$ & & 5 & $4.85 \pm 0.41$ & $97.0 \pm 8.5$ & & 1 & $0.95 \pm 0.09$ & $95.0 \pm 9.5$ \\
\hline & 2 & $1.95 \pm 0.15$ & $97.0 \pm 7.6$ & $\mathrm{La}$ & 0 & BDL & - & & 2 & $1.85 \pm 0.17$ & $92.5 \pm 8.5$ \\
\hline & 5 & $4.89 \pm 0.25$ & $97.6 \pm 5.1$ & & 1 & $0.95 \pm 0.08$ & $95.0 \pm 8.4$ & & 5 & $4.51 \pm 0.45$ & $90.2 \pm 9.0$ \\
\hline \multirow[t]{4}{*}{$\mathrm{Ce}$} & 0 & $0.10 \pm 0.007$ & - & & 2 & $1.89 \pm 0.16$ & $94.5 \pm 8.0$ & \multirow[t]{4}{*}{$\mathrm{Sm}$} & 0 & BDL & - \\
\hline & 1 & $1.08 \pm 0.04$ & $98.0 \pm 7.7$ & & 5 & $4.86 \pm 0.41$ & $97.2 \pm 8.4$ & & 1 & $0.98 \pm 0.05$ & $98.0 \pm 5.1$ \\
\hline & 2 & $2.05 \pm 0.10$ & $97.5 \pm 8.3$ & $\mathrm{Lu}$ & 0 & BDL & - & & 2 & $1.92 \pm 0.10$ & $96.0 \pm 5.2$ \\
\hline & 5 & $5.08 \pm 0.20$ & $99.6 \pm 8.0$ & & 1 & $0.97 \pm 0.09$ & $97.0 \pm 9.0$ & & 5 & $4.89 \pm 0.26$ & $97.8 \pm 5.3$ \\
\hline \multirow[t]{4}{*}{ Co } & 0 & $0.11 \pm 0.01$ & - & & 2 & $1.90 \pm 0.15$ & $95.0 \pm 7.5$ & \multirow[t]{4}{*}{$\mathrm{Tb}$} & 0 & BDL & - \\
\hline & 1 & $1.09 \pm 0.05$ & $98.0 \pm 9.9$ & & 5 & $4.95 \pm 0.45$ & $99.00 \pm 9.0$ & & 1 & $0.92 \pm 0.07$ & $92.0 \pm 7.6$ \\
\hline & 2 & $1.99 \pm 0.09$ & $94.0 \pm 9.5$ & $\mathrm{Mg}$ & 0 & $2.6 \pm 0.16$ & - & & 2 & $1.88 \pm 0.11$ & $94.0 \pm 5.8$ \\
\hline & 5 & $5.10 \pm 0.20$ & $99.8 \pm 9.9$ & & 1 & $3.55 \pm 0.28$ & $95.0 \pm 8.5$ & & 5 & $4.79 \pm 0.27$ & $95.8 \pm 5.6$ \\
\hline \multirow[t]{4}{*}{$\mathrm{Cr}$} & 0 & $2.90 \pm 0.15$ & - & & 2 & $4.52 \pm 0.31$ & $96.0 \pm 8.4$ & \multirow[t]{4}{*}{$\mathrm{Te}$} & 0 & $0.51 \pm 0.02$ & - \\
\hline & 1 & $3.85 \pm 0.25$ & $95.0 \pm 7.9$ & & 5 & $7.54 \pm 0.56$ & $98.8 \pm 9.5$ & & 1 & $1.48 \pm 0.15$ & $97.0 \pm 8.1$ \\
\hline & 2 & $4.89 \pm 0.31$ & $99.5 \pm 8.1$ & Mn & 0 & $1.80 \pm 0.15$ & - & & 2 & $2.41 \pm 0.13$ & $95.0 \pm 6.3$ \\
\hline & 5 & $7.87 \pm 0.55$ & $99.4 \pm 8.6$ & & 1 & $2.75 \pm 0.25$ & $95.0 \pm 7.4$ & & 5 & $5.39 \pm 0.29$ & $97.6 \pm 6.5$ \\
\hline \multirow[t]{4}{*}{ Cs } & 0 & $0.10 \pm 0.008$ & - & & 2 & $3.77 \pm 0.35$ & $98.5 \pm 7.7$ & $\mathrm{Tm}$ & 0 & BDL & - \\
\hline & 1 & $1.09 \pm 0.05$ & $99.0 \pm 9.1$ & & 5 & $6.70 \pm 0.65$ & $98.0 \pm 8.1$ & & 1 & $0.91 \pm 0.09$ & $91.0 \pm 9.9$ \\
\hline & 2 & $2.05 \pm 0.10$ & $97.5 \pm 9.1$ & $\mathrm{Nd}$ & 0 & BDL & - & & 2 & $1.85 \pm 0.16$ & $92.5 \pm 8.0$ \\
\hline & 5 & $4.95 \pm 0.25$ & $97.0 \pm 9.2$ & & 1 & $0.98 \pm 0.07$ & $98.0 \pm 7.1$ & & 5 & $4.80 \pm 0.42$ & $96.0 \pm 8.6$ \\
\hline $\mathrm{Cu}$ & 0 & $2.91 \pm 0.13$ & - & & 2 & $1.93 \pm 0.15$ & $97.5 \pm 7.5$ & V & 0 & $0.10 \pm 0.005$ & - \\
\hline & 1 & $3.90 \pm 0.25$ & $99.0 \pm 7.7$ & & 5 & $4.95 \pm 0.35$ & $99.0 \pm 7.1$ & & 1 & $1.08 \pm 0.05$ & $98.0 \pm 6.8$ \\
\hline & 2 & $4.92 \pm 0.30$ & $100.5 \pm 7.6$ & $\mathrm{Ni}$ & 0 & $4.51 \pm 0.24$ & - & & 2 & $2.06 \pm 0.11$ & $98.0 \pm 7.2$ \\
\hline & 5 & $8.00 \pm 0.60$ & $101.8 \pm 8.9$ & & 1 & $5.49 \pm 0.30$ & $98.0 \pm 7.5$ & & 5 & $5.01 \pm 0.25$ & $98.2 \pm 6.9$ \\
\hline Dy & 0 & BDL & - & & 2 & $6.48 \pm 0.35$ & $98.5 \pm 9.2$ & $\mathrm{Y}$ & 0 & $0.25 \pm 0.02$ & - \\
\hline & 1 & $0.98 \pm 0.09$ & $98.0 \pm 9.2$ & & 5 & $9.44 \pm 0.55$ & $98.6 \pm 7.8$ & & 1 & $1.22 \pm 0.07$ & $97.0 \pm 9.5$ \\
\hline & 2 & $1.95 \pm 0.15$ & $97.5 \pm 7.5$ & $\mathrm{~Pb}$ & 0 & $0.65 \pm 0.05$ & - & & 2 & $2.21 \pm 0.12$ & $98.0 \pm 9.5$ \\
\hline & 5 & $4.99 \pm 0.45$ & $99.8 \pm 9.0$ & & 1 & $1.59 \pm 0.11$ & $94.0 \pm 9.7$ & & 5 & $5.21 \pm 0.31$ & $99.2 \pm 9.9$ \\
\hline $\mathrm{Eu}$ & 0 & $0.10 \pm 0.006$ & - & & 2 & $2.56 \pm 0.19$ & $95.5 \pm 8.0$ & $\mathrm{Yb}$ & 0 & BDL & - \\
\hline & 1 & $1.12 \pm 0.03$ & $102.0 \pm 6.2$ & & 5 & $5.61 \pm 0.35$ & $99.2 \pm 9.8$ & & 1 & $0.95 \pm 0.09$ & $95.0 \pm 9.4$ \\
\hline & 2 & $1.99 \pm 0.11$ & $94.4 \pm 7.7$ & $\operatorname{Pr}$ & 0 & BDL & - & & 2 & $1.88 \pm 0.15$ & $94.0 \pm 7.5$ \\
\hline & 5 & $5.14 \pm 0.22$ & $100.8 \pm 7.4$ & & 1 & $0.98 \pm 0.05$ & $98.0 \pm 5.1$ & & & & \\
\hline Er & 0 & BDL & - & & 2 & $1.91 \pm 0.11$ & $95.5 \pm 5.6$ & & & & \\
\hline & 1 & $0.95 \pm 0.09$ & $95.0 \pm 9.5$ & & 5 & $4.89 \pm 0.25$ & $97.8 \pm 5.1$ & & & & \\
\hline & 2 & $1.96 \pm 0.15$ & $98.0 \pm 7.5$ & $\mathrm{Pt}$ & 0 & BDL & - & & & & \\
\hline & 5 & $4.85 \pm 0.40$ & $97.0 \pm 8.0$ & & 1 & $0.89 \pm 0.08$ & $89.0 \pm 9.0$ & & & & \\
\hline $\mathrm{Ga}$ & 0 & $0.3 \pm 0.02$ & - & & 2 & $1.78 \pm 0.15$ & $89.0 \pm 7.5$ & & & & \\
\hline & 1 & $1.25 \pm 0.09$ & $95.0 \pm 9.3$ & & 5 & $4.55 \pm 0.48$ & $91.0 \pm 9.6$ & & & & \\
\hline
\end{tabular}




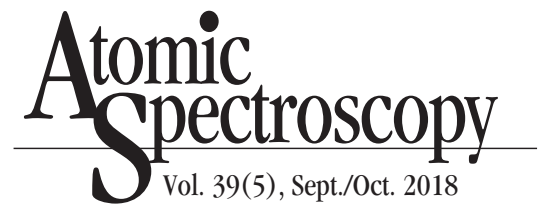

TABLE $V$

Trace Element Concentration

in the U-Zr Samples of Different Lots (in $\mu \mathrm{g} \mathrm{g}^{-1}$ )

\begin{tabular}{|c|c|c|c|}
\hline Elements & Sample I & Sample II & Sample III \\
\hline $\mathrm{Al}$ & $960 \pm 70$ & $1370 \pm 105$ & $650 \pm 45$ \\
\hline $\mathrm{Ba}$ & $2.81 \pm 1.5$ & $1.77 \pm 0.15$ & $1.32 \pm 0.11$ \\
\hline $\mathrm{Bi}$ & $1.43 \pm 0.10$ & $0.29 \pm 0.02$ & $0.22 \pm 0.02$ \\
\hline $\mathrm{Cd}$ & $0.63 \pm 0.60$ & $0.28 \pm 0.02$ & $0.25 \pm 0.02$ \\
\hline $\mathrm{Ce}$ & $1.24 \pm 0.11$ & $1.36 \pm 0.11$ & $0.63 \pm 0.06$ \\
\hline $\mathrm{Co}$ & $20.72 \pm 1.84$ & $19.47 \pm 1.55$ & $0.49 \pm 0.05$ \\
\hline $\mathrm{Cr}$ & $3000 \pm 150$ & $1100 \pm 65$ & $64.0 \pm 4.5$ \\
\hline Cs & $20.0 \pm 0.9$ & $15.5 \pm 1.0$ & $5.0 \pm 0.2$ \\
\hline $\mathrm{Cu}$ & $85.16 \pm 7.5$ & $272.74 \pm 25.5$ & $20.86 \pm 2.05$ \\
\hline Dy & $4.65 \pm 0.41$ & $3.04 \pm 0.30$ & $3.92 \pm 0.31$ \\
\hline $\mathrm{Eu}$ & $\mathrm{BDL}^{*}$ & $\mathrm{BDL}$ & $\mathrm{BDL}$ \\
\hline Er & $2.44 \pm 0.22$ & $2.31 \pm 0.21$ & $2.05 \pm 0.20$ \\
\hline $\mathrm{Ga}$ & $6.81 \pm 0.55$ & $7.37 \pm 0.72$ & $0.83 \pm 0.08$ \\
\hline Gd & $0.52 \pm 0.05$ & $0.07 \pm 0.007$ & $\mathrm{BDL}$ \\
\hline Ir & $0.61 \pm 0.06$ & $0.25 \pm 0.02$ & $0.26 \pm 0.02$ \\
\hline Ho & $3.86 \pm 0.25$ & $3.48 \pm 0.31$ & $2.94 \pm 0.25$ \\
\hline $\mathrm{La}$ & $0.39 \pm 0.04$ & $0.31 \pm 0.03$ & $0.05 \pm 0.005$ \\
\hline $\mathrm{Lu}$ & BDL & BDL & $\mathrm{BDL}$ \\
\hline Mg & $30.58 \pm 2.91$ & $38.15 \pm 3.51$ & $37.83 \pm 3.33$ \\
\hline Mn & $301.28 \pm 25.5$ & $57.71 \pm 4.89$ & $8.82 \pm 0.75$ \\
\hline $\mathrm{Nd}$ & $0.47 \pm 0.04$ & $0.63 \pm 0.06$ & $0.06 \pm 0.006$ \\
\hline $\mathrm{Ni}$ & $1732 \pm 200$ & $4389 \pm 450$ & $95.5 .0 \pm 4.8$ \\
\hline $\mathrm{Pb}$ & $3.15 \pm 0.25$ & $2.55 \pm 0.21$ & $4.37 \pm 0.41$ \\
\hline $\operatorname{Pr}$ & $0.13 \pm 0.01$ & $\mathrm{BDL}$ & $\mathrm{BDL}$ \\
\hline $\mathrm{Pt}$ & $0.03 \pm 0.003$ & $\mathrm{BDL}$ & BDL \\
\hline $\mathrm{Rb}$ & $0.78 \pm 0.07$ & $0.23 \pm 0.02$ & $\mathrm{BDL}$ \\
\hline $\mathrm{Rh}$ & $0.43 \pm 0.04$ & $0.04 \pm 0.004$ & $0.01 \pm 0.001$ \\
\hline $\mathrm{Ru}$ & $0.66 \pm 0.06$ & $0.21 \pm 0.02$ & $0.15 \pm 0.01$ \\
\hline Sc & $44.96 \pm 4.5$ & $26.44 \pm 2.11$ & $18.26 \pm 1.55$ \\
\hline $\mathrm{Sm}$ & $0.02 \pm 0.002$ & BDL & BDL \\
\hline $\mathrm{Tb}$ & $0.03 \pm 0.002$ & $\mathrm{BDL}$ & $\mathrm{BDL}$ \\
\hline $\mathrm{Te}$ & $3.68 \pm 0.31$ & $1.72 \pm 0.15$ & $1.51 \pm 0.11$ \\
\hline $\mathrm{Tm}$ & $0.09 \pm 0.009$ & $\mathrm{BDL}$ & $\mathrm{BDL}$ \\
\hline V & $309.12 \pm 30.11$ & $383.6 \pm 35.55$ & $29.82 \pm 2.65$ \\
\hline $\mathrm{Y}$ & $2.03 \pm 0.021$ & $121.19 \pm 10.51$ & $11.41 \pm 1.12$ \\
\hline $\mathrm{Yb}$ & $0.45 \pm 0.04$ & $0.13 \pm 0.01$ & $\mathrm{BDL}$ \\
\hline
\end{tabular}

*Below detection limit (i.e. MDL)

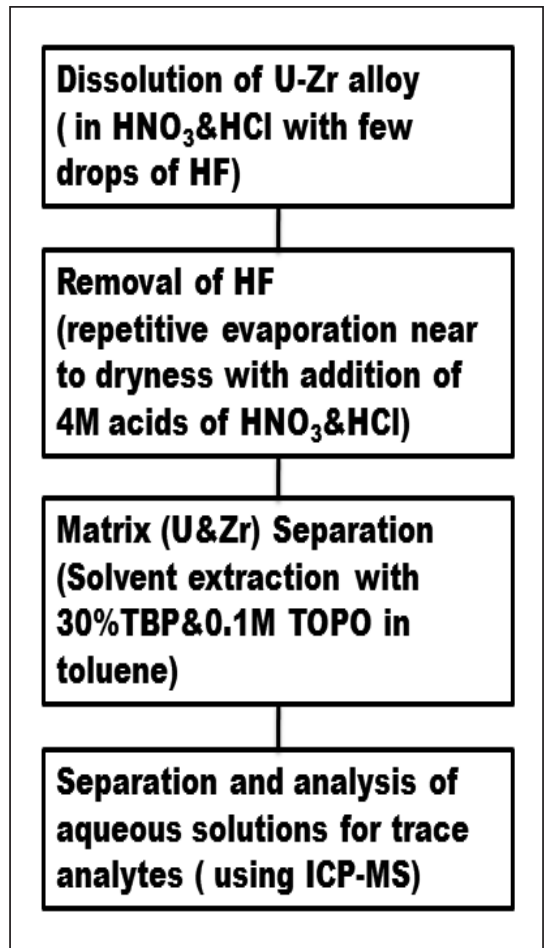

Fig. 4. Systematic diagram for analysis of $U$-Zr alloy.

\section{Analysis of Real Samples}

Analysis of real U-Zr alloy samples of different lots was carried out following the methodology described above. The flow diagram for the final optimized procedure is given in Figure 4, and the results are listed in Table V.

\section{CONCLUSION}

A method, based on solvent extraction of the major matrix, followed by the determination of impurity concentrations using ICPMS, has been standardized for the analysis of trace level impurities in $\mathrm{U}-\mathrm{Zr}$. The solvent extraction method is fast and effective for the separation of trace elements from the U-Zr matrix. It was found that 36 elements can be quantitatively separated from the matrix. The methodology herein proposed led to low detection limits for quantification of trace and ultra-trace elements for $\mathrm{U}-\mathrm{Zr}$ alloy $\left(1.0-25.0 \mu \mathrm{g} \mathrm{\textrm {L } ^ { - 1 }}\right)$. 
Recovery of the trace elements in spiked solution was quantitative (91-102.4\%). This method could be used to analyze U-Zr alloy nuclear fuel samples for 36 elements (Al, $\mathrm{Ba}, \mathrm{Bi}, \mathrm{Cd}, \mathrm{Ce}, \mathrm{Co}, \mathrm{Cr}, \mathrm{Cu}, \mathrm{Dy}, \mathrm{Eu}$, Er, Ga, Gd, Ir, La, Lu, Mg, Mn, Nd, $\mathrm{Ni}, \mathrm{Nb}, \mathrm{Pb}, \mathrm{Pr}, \mathrm{Pt}, \mathrm{Rb}, \mathrm{Rh}, \mathrm{Ru}, \mathrm{Sc}$, $\mathrm{Sm}, \mathrm{Sr}, \mathrm{Tb}, \mathrm{Te}, \mathrm{Tm}, \mathrm{V}, \mathrm{Y}$, and $\mathrm{Yb}$ ) with good accuracy and precision.

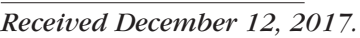

\section{REFERENCES}

1. A. Riyas, and P. Mohanakrishanan, Ann. Nucl. Energy 35,87 (2008).

2. R. K. Sinha, Advanced Nuclear Reactor System- An Indian Perspective, Energy Procedure 7,34 (2011).

3. Y. Hu,M.and Xu, Nucl. Power Eng. 1, 53 (2008).

4. X.M. Shi, and X.J.Peng, Nucl. Power Eng. 4, 5 (2010).

5. International Conference on Fast Reactors and Related Fuel Cycles: March 4-7,(2013), Paris, France.

6. ASTM C753-04 (2009) Standard specification for nuclear grade sinterable uranium dioxide powder

7. A.L. de Souza, M.E.B. Cotrim, and M.A.F. Pires, Microchem. J. 106, 194 (2013).

8. A. Taylor, N. Barlow, M. P.Day, S. Hill, M. Patriarca, and M. White, J. Anal. At. Spectrom. 32, 432 (2017).

9. S. Carter, A. Fisher, R. Garcia, B. Gibson, S. Lancaster, J. Marshall, and I. WhitesideJ. Anal. At. Spectrom. 30, 2249 (2015).

10. A. Saha, S.B. Deb, B.K. Nagar, and M.K. Saxena, At. Spectrosc. 34(4), 125 (2013)

11. A. Saha, S.B. Deb, and M.K. Saxena, J. Anal. At. Spectrom. 31, 1480 (2016).

12. A. Sengupta, B. Rajeswari, R.M. Kadam, and S.V. Godbole, Atom. Spectrosc. 33(2), 48 (2012).

13. V.G. Mishra, S.K. Sali, D.J.Shah, U.K. Thakur, R.M. Sawant, and B.S. Tomar, Radiochim. Acta 102(10), 895 (2014)
14. B.S. Mohite, and S.H. Burungale, J. Radioanal. Nucl. Ch. 241(3), 589 (1999).

15. G. Jin-xin, S. Si-xie, D. Dong-li, L. Ming-xia, P. Hua, and M. Zhao-li, J. Radioanal. Nucl. Ch. 267(3), 675 (2006).

16. S.D. Dogmane, R.K. Singh, D.D. Bajpai, and J.N. Mathur, J. Radioanal. Nucl. Ch. 253(3) 477 (2002).

17. S.I.El-Dessouky, J. Radioanal. Nucl. Ch. 260(3), 613 (2004).

18. I. Haiduc, M. Curtui, and I. Haiduc, J. Radioanal. Nucl. Ch. 99(2), 257 (1986).

19. Y. Xing-Cun, B. Bo-Rong, and C. Wi Guo, J. Radioanal. Nucl. Ch. 258(3), 681 (2003).

20. N.V. Deorkar, and S.M. Khopkar, J. Radioanal. Nucl. Ch. 130(2), 433 (1989).

21. M. Jankowska, J. Kulawik, and J Mikulski, J. Radioanal. Nucl. Ch 31,9 (1976)

22. B. Tamhina, A. Gojmerac, and M.J. Herak, Laboratory of Analytical Chemistry, Faculty of Science, Zagreb, Yugoslavia 569 (1976).

23. J.A. Daoud,N.A. Rahman, and H.F. Aly, J. Radioanal. Nucl. Ch. 221(12), 41 (1997).

24. Y. Shigetomi, T. Kojima, and H. Kamba, J. Nucl. Sci. Technol. 20(2), 140 (1983).

25. C. A. Horton, and J.C. White, Anal. Chem. 30(11), 1779 (1958).

26. L. Poriel, A. F. Reguillon, S.P. Rostaing, and M. Lemaire, Sep. Sci. and Technol. 41, 1927 (2006).

27. R. Banda, H. Young lee, and M. S. Lee, J. Radioanal. Nucl. Ch. 295, 1537(2013).

28. M. Taghizadeh, M. Ghanadi, and E. Zolfonoun, J. Nucl. Mater. 412, 334 (2011).

29. A. Sadigzadeh, S. Chehrenama, and H. Shokri, J. Theor. Appl. Phys. 3(3), 20 (2009).

30. L.Y. Wang, H.Y. Lee, and M.S. Lee, Mater. Trans. 54, 1460 (2013).

31. S.A. Mohammed, J. Raf. Sci. 20(2), 74 (2009).

32. R. Sarkar (Sain), S. Ray, and S.
Basu, J. Chem. Bio. Phy. Sec. A 4(4), 3156 (2014).

33. T. Sato, Solvent Extr. Ion Exc. 1(2), 251 (1983).

34. L.Y. Wang, H.Y. Lee, and M.S. Lee, Mater. Trans. 54 (8), 1460 (2013).

35. B.K. Nagar, M.K. Saxena, and B.S. Tomar, At. Spectrosc. 38(5), 117 (2017).

36. S.A. Sheweita, M.A.El-Gabar, and M.Bastawy, Toxicology 169, 83 (2001).

37. L. Jauberty, N. Drogat, J. L. Decossas, V. Delpech, V. Gloaguen, and V. Sol, Talanta 115, 751 (2013).

38. R. Chiarizia, D.C. Stepinski, and P. Thyagarajan, Sep. Sci. Technol. 41, 2075 (2006)

39. I.V. Blazheva, Y.S. Fedorov, B. Ya. Zilberman, and L.G. Mashirov, Radiochem. 50(3), 256 (2008).

40. D. Das, V.A. Juvekar, S.B. Roy, and R. Bhattacharya, J. Radioanal. Nucl. Ch. 300, 333 (2014).

41. J.M. Fletcher and C.J. Hardy, Nucl. Sci. Eng. 16, 421 (1963).

42. E. Hesford and A.C. Mckay, Trans.Faraday Soc. 54, 573 (1958).

43. S.H. Tan, and G. Horlick, J. Anal. At. Spectrom. 2, 745 (1987).

44. A. S. Al-Ammar, R.K. Gupta, and R.M. Barnes, Spectrochim. Acta Part B 54, 1849 (1999).

45. T.W. Burgoyne, G.M. Hieftje, and R.A. Hites, Anal. Chem. 69, 485 (1997).

46. M.A.Vaughan and G. Horlick, Appl. Spectrosc. 40(4), 434 (1986).

47. A. L. Gray and J. G. Williams, J. Anal. At. Spectrom. 2, 599 (1987).

48. F. Vanhaecke, C. Vandecasteele, $H$. Vanhoce, and R. Dams, Microchim. Acta 108, 41 (1992).

49. T.S. Lum and S.Y. Leung, J. Anal At. Spectrom. 31,1078 (2016).

50. N.M. Raut, L.S. Haung, S.K. Aggrawal, and K.C. Lin, J. Chin. Chem. Soc. 52, 589 (2005).

51. M. Belter, A. Sajnog, and D. Barlkiewtcz, Talanta 129, 606 (2014). 